\title{
Chemical origin of the yellow luminescence in GaN
}

\author{
S. O. Kucheyeva) \\ Department of Electronic Materials Engineering, Research School of Physical Sciences and Engineering, \\ The Australian National University, Canberra, ACT 0200, Australia \\ M. Toth ${ }^{\text {b) }}$ and M. R. Phillips \\ Microstructural Analysis Unit, University of Technology, Sydney, Broadway, NSW 2007, Australia
}

J. S. Williams and C. Jagadish

Department of Electronic Materials Engineering, Research School of Physical Sciences and Engineering, The Australian National University, Canberra, ACT 0200, Australia

G. Li

Ledex Corporation, No. 9, Ta-Yio First St., Ta-Fa Industrial District, Kaohsiung County, Taiwan, Republic of China

(Received 11 July 2001; accepted for publication 14 February 2002)

\begin{abstract}
The influence of ion-beam-produced lattice defects as well as $\mathrm{H}, \mathrm{B}, \mathrm{C}, \mathrm{N}, \mathrm{O}$, and $\mathrm{Si}$, introduced by ion implantation, on the luminescence properties of wurtzite $\mathrm{GaN}$ is studied by cathodoluminescence spectroscopy. Results indicate that intrinsic lattice defects produced by ion bombardment mainly act as nonradiative recombination centers and do not give rise to the yellow luminescence (YL) of GaN. Experimental data unequivocally shows that $\mathrm{C}$ is involved in the defect-impurity complex responsible for YL. In addition, C-related complexes appear to act as efficient nonradiative recombination centers. Implantation of $\mathrm{H}$ produces a broad luminescent peak which is slightly blueshifted with respect to the C-related YL band in the case of high excitation densities. The position of this H-related YL peak exhibits a blueshift with increasing excitation density. Based on this experimental data and results reported previously, the chemical origin of the YL band is discussed. (C) 2002 American Institute of Physics. [DOI: 10.1063/1.1467605]
\end{abstract}

\section{INTRODUCTION}

Research interest in GaN has been driven by significant technological importance of this material. Indeed, $\mathrm{GaN}$ is used in the fabrication of a range of electronic and photonic devices. ${ }^{1}$ Due to such technological importance, considerable research effort has been made to understand the fundamental properties of GaN. ${ }^{1}$ In particular, its optical characteristics have received extensive attention due to their importance for GaN-based optoelectronic devices.

One of the GaN luminescent peaks, which has attracted considerable research interest, is the so-called yellow luminescence (YL) band. This ubiquitous broad luminescent peak centered on $\sim 2.2 \mathrm{eV}$ (at $300 \mathrm{~K}$ ) has been observed in $\mathrm{GaN}$ grown by different techniques and in different laboratories. ${ }^{1}$ In optoelectronic devices, YL is highly undesirable since it represents a competing recombination path which reduces the intensity of near-gap emission.

A large number of studies have been reported in the literature on the origin and properties of YL (see, for example, Refs. 2-38). The YL band and related deep states have been studied both theoretically (see, for example, Refs. 10, 16, and 23) and experimentally by cathodoluminescence (CL) (see, for example, Refs. 11, 12, 24, 30, 31, and 33),

\footnotetext{
${ }^{a)}$ Electronic mail: sergei.kucheyev@anu.edu.au

${ }^{b)}$ Present address: Polymers and Colloids Group, Cavendish Laboratory, University of Cambridge, Madingley Road, Cambridge, CB3 0HE, United Kingdom.
}

photoluminescence (see, for example, Refs. 2-9, 12-15, $18-22,25-29,32$, and 36), photocapacitance, ${ }^{15}$ photoionization spectroscopy, ${ }^{38}$ deep level transient spectroscopy (DLTS), ${ }^{15,37}$ magnetic resonance, ${ }^{4,5,34,35}$ positron annihilation, ${ }^{17}$ photoconductivity, ${ }^{18,19}$ and surface photovoltage spectroscopy. ${ }^{26}$ Experimental data reported in the literature strongly suggests that the YL band can be attributed to a radiative transition between shallow donors (or the conduction band) and some deep traps (of either donor or acceptor nature). ${ }^{39}$ This mechanism for YL was originally proposed in an early work on this topic by Ogino and Aoki. ${ }^{3}$ The broad nature of the YL band is typical for deep centers in semiconductors, given a strong electron-phonon interaction. ${ }^{40}$

In contrast to some apparent agreement on the most plausible scenario for the electronic levels involved in the radiative transition responsible for YL, the chemical origin of the YL band (and, hence, an unequivocal microscopic model for the center responsible for YL) remains a subject of strong debate. In particular, it is still not clear whether the center responsible for $\mathrm{YL}$ is of an intrinsic (i.e., due to native lattice defects alone) or of extrinsic (i.e., impurity-related) origin. Such a situation exists partly because most of the experimental techniques used to study $\mathrm{YL}$ in $\mathrm{GaN}$ are essentially "chemically blind" and allow much room for speculations about the chemical origin of the YL band.

Because YL is generally found in GaN grown by different techniques, it has been widely believed that intrinsic lattice defects (such as simple point defects or extended defects) participate in the formation of YL. ${ }^{1}$ This conclusion 
was apparently supported by early ion implantation studies. ${ }^{2}$ Indeed, Pankove and Hutchby ${ }^{2}$ performed implantation of 35 different species into $\mathrm{GaN}$ and found that most of the implants resulted in a strong increase in the intensity of YL, measured after postimplantation annealing. As a result, it has been suggested that point defects (which can be produced by ion bombardment) are responsible for YL. ${ }^{2,3}$ To our knowledge, this ion implantation report by Pankove and Hutchby ${ }^{2}$ is the only "direct" experimental evidence in favor of intrinsic point defects as the origin of YL. In this article, we will discuss the results reported by Pankove and Hutchby ${ }^{2}$ in view of more recent ion implantation data and show that implantation-produced lattice defects alone do not give rise to YL.

Many authors have suggested that different impurities such as C (Refs. 3, 7, 14, 20, 21, 28, 32, and 38), O (Refs. 23, 24, 30, and 31), H (Refs. 20 and 22), or Si (Refs. 27, 30, and 36) participate in the formation of YL. For example, even one of the first detailed studies of YL in GaN by Ogino and $\mathrm{Aoki}^{3}$ has shown that doping with $\mathrm{C}$ during crystal growth strongly emphasizes the YL band. However, based on this result and on ion implantation data reported by Pankove and Hutchby, ${ }^{2}$ Ogino and Aoki attributed the origin of YL to a complex consisting of a Ga vacancy and some impurity (not necessarily C). ${ }^{3}$ They have also proposed that the Ga vacancy determines the electronic level of the complex, and, hence, emission energy is independent of the impurity species, in agreement with the experimental data available at that time. ${ }^{3}$

In this article, we discuss the chemical origin of YL, an understanding of which is very important for (i) the control of undesirable YL in GaN-based optoelectronic devices and (ii) the development of an adequate microscopic model for the center responsible for YL. To study the chemical origin of YL we have performed an optical doping of GaN with potential impurities which are always unintentionally introduced into GaN during crystal growth (such as $\mathrm{H}, \mathrm{C}, \mathrm{O}$, and $\mathrm{Si}$ ) as well as with neutral species (such as N). Optical doping was done by ion implantation, a technique often used to introduce dopants in a well controlled manner. However, ion implantation inevitably produces lattice disorder. Hence, we first address the effects of ion-beam-produced lattice defects on the optical properties of GaN. An understanding of such effects is not only important to ascertain the role of intrinsic lattice defects in the formation of YL but is also vital for a correct interpretation of luminescence spectra from GaN optically doped by ion implantation.

\section{EXPERIMENT}

The samples used in this study were cut from six wafers of $\sim 2 \mu \mathrm{m}$ thick wurtzite $\mathrm{GaN}$ epilayers grown on $c$-plane sapphire substrates by metalorganic chemical vapor deposition (MOCVD) in three different EMCORE reactors. Both nominally undoped and Si-doped $\mathrm{GaN}$ wafers were used. The samples were implanted at room temperature with $\mathrm{keV}$ ${ }^{1} \mathrm{H},{ }^{11} \mathrm{~B},{ }^{12} \mathrm{C},{ }^{14} \mathrm{~N},{ }^{16} \mathrm{O}$, or ${ }^{28} \mathrm{Si}$ ions using the ANU $180 \mathrm{kV}$ ion implanter or an ANU 1.7 MV tandem accelerator (NEC,
TABLE I. Free electron concentration $(n)$ and effective Hall mobility ( $\left.\mu_{\text {eff }}\right)$ of the three $\mathrm{GaN}$ wafers used in sequential implantation experiments.

\begin{tabular}{cccc}
\hline \hline Wafer & Grower & $n\left(10^{16} \mathrm{~cm}^{-3}\right)$ & $\mu_{\text {eff }}\left(\mathrm{cm}^{2} \mathrm{~V}^{-1} \mathrm{~s}^{-1}\right)$ \\
\hline A & IMRE & 4 & 144 \\
B & EMCORE & $\leqslant 1$ & 90 \\
C & Ledex & 0.5 & 90 \\
\hline \hline
\end{tabular}

${ }^{2}$ Institute of Materials Research and Engineering, Singapore.

5SDH-4). During implantation, samples were tilted by $\sim 7^{\circ}$ relative to the incident ion beam to minimize channeling.

As will be shown below, from the species listed above, $\mathrm{H}, \mathrm{C}$, and $\mathrm{O}$ have been found to be involved in YL. Therefore, using successive masking before each implantation step, we performed identical sequential implantation of $\mathrm{H}, \mathrm{C}$, and $\mathrm{O}$ into $\mathrm{GaN}$ samples cut from three representative wafers (A, B, and C) grown in different laboratories. The electrical characteristics of these wafers are given in Table I, as assessed by Hall effect measurements or specified by the grower. Sequential ion implantation was performed so that, at the end of the implant sequence, each sample had the following areas: (i) virgin (as-grown) material, masked during all implantion steps; (ii) implanted with $\mathrm{C}$; (iii) implanted with $\mathrm{O}$; (iv) implanted with $\mathrm{H}$; (v) implanted with $\mathrm{C}$ and $\mathrm{O}$; (vi) implanted with $\mathrm{C}$ and $\mathrm{H}$; (vii) implanted with $\mathrm{O}$ and $\mathrm{H}$; and (viii) implanted with all three species $(\mathrm{C}, \mathrm{O}$, and $\mathrm{H})$. The details of implant conditions used to prepare these samples are given in Table II. The energies of $\mathrm{C}, \mathrm{O}$, and $\mathrm{H}$ ions shown in this table have been chosen so that the depth profiles of implanted species closely overlap, as can be seen from projected ion ranges, calculated using the TRIM code, ${ }^{41}$ as given in Table II.

Postimplantation annealing was carried out in a rapid thermal annealing (RTA) system in a nitrogen ambient at atmospheric pressure. The annealing was performed in the proximity geometry ${ }^{1}$ in order to minimize material decomposition. CL measurements were carried out at 77 and $300 \mathrm{~K}$ using an Oxford Instruments MonoCL2 system installed on a JEOL 35C scanning electron microscope and equipped with a cold stage. During data acquisition, a finely focused electron beam was scanned over a frame of $\sim 80 \times 100 \mu \mathrm{m}^{2}$ at a rate of 10 frames/s. CL kinetics profiling was done in spot mode with a finely focused electron beam. Excitation measurements were performed by changing electron beam current, while maintaining a finely focused electron beam. The CL signal was dispersed by a $1200-$ lines/mm grating blazed

TABLE II. The implant conditions used to introduce $\mathrm{C}, \mathrm{O}$, and $\mathrm{H}$ species into $\mathrm{GaN}$ by sequential ion implantation at $300 \mathrm{~K}$. Calculated values of projected ion ranges $\left(R_{p}\right)$ and the average number of lattice vacancies produced by one ion $\left(N_{\mathrm{vac}}\right)$ are also given.

\begin{tabular}{cccccrr}
\hline $\begin{array}{c}\text { Implant } \\
\text { order }\end{array}$ & Ion & $\begin{array}{c}\text { Energy } \\
(\mathrm{keV})\end{array}$ & $\begin{array}{c}\text { Dose } \\
\left(10^{14} \mathrm{~cm}^{-2}\right)\end{array}$ & $\begin{array}{c}\text { Beam flux } \\
\left(10^{11} \mathrm{~cm}^{-2} \mathrm{~s}^{-1}\right)\end{array}$ & $\begin{array}{c}R_{p} \\
(\AA)\end{array}$ & $N_{\text {vac }}$ \\
\hline 1 & ${ }^{12} \mathrm{C}$ & 120 & 1 & 5.5 & 1945 & 946 \\
2 & ${ }^{16} \mathrm{O}$ & 150 & 1 & 5.5 & 1890 & 1429 \\
3 & ${ }^{1} \mathrm{H}$ & 25 & 1 & 5.5 & 1995 & 17 \\
\hline \hline
\end{tabular}




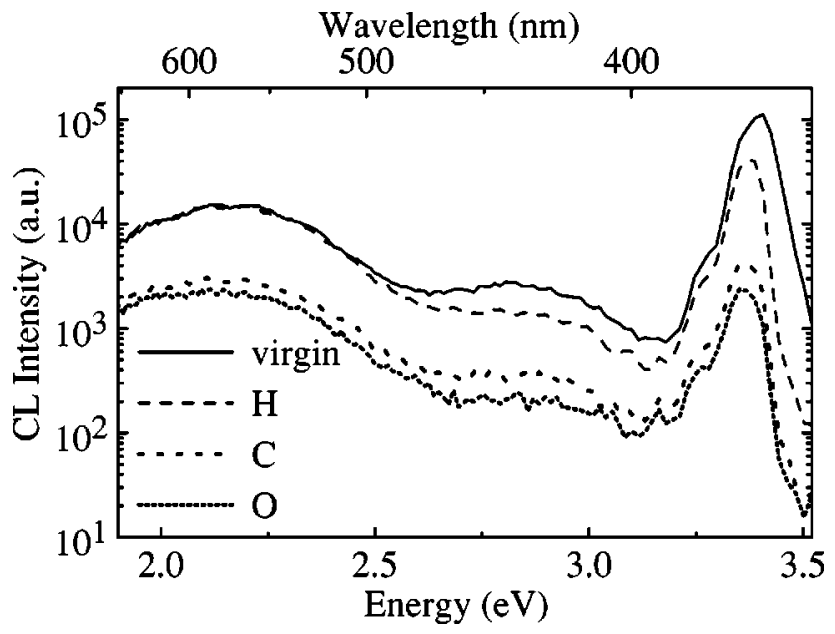

FIG. 1. CL spectra obtained at $300 \mathrm{~K}$ from as-grown $\mathrm{GaN}$ and $\mathrm{GaN}$ implanted with $\mathrm{H}, \mathrm{C}$, and $\mathrm{O}$ ions, as indicated in the legend (wafer $\mathrm{C}$, electron beam energy $=20 \mathrm{keV}$, electron beam current $=8.6 \mathrm{nA}, \mathrm{CL}$ bandpass $=2.5$ $\mathrm{nm})$. The details of implant conditions are given in Table II.

at $500 \mathrm{~nm}$ and detected using a Hamamatsu R943-02 peltier cooled photomultiplier tube. CL spectra were corrected for system response.

\section{RESULTS AND DISCUSSION}

\section{A. Effect of implantation damage}

An energetic light ion traversing a GaN crystal generates a collision cascade which primarily consists of Frenkel pairs (i.e., vacancies and interstitials) in both gallium and nitrogen sublattices. As discussed in detail elsewhere, ${ }^{42}$ these simple point defects appear to be mobile in $\mathrm{GaN}$ at room temperature, and most of them experience annihilation. ${ }^{43}$ However, such dynamic annealing processes are not perfect, and some point defect complexes form in the GaN crystal as a result of ion bombardment. ${ }^{42}$ These implantation-produced defect complexes significantly affect the optical properties of GaN, which we discuss below.

Typical CL spectra of as-implanted GaN (without postimplantation annealing), illustrating the effects of implantation-produced lattice defects on the luminescence of GaN, are shown in Fig. 1. These spectra, obtained at $300 \mathrm{~K}$, consist of near-gap emission (centered on $\sim 3.39 \mathrm{eV}$ ), blue luminescence (a broad CL peak centered on $\sim 2.82 \mathrm{eV}$ ), and the YL band (centered on $\sim 2.15 \mathrm{eV}$ ). The ripples usually visible in the YL band can be attributed to the microcavity effect. $^{44}$

It is seen from Fig. 1 that ion implantation considerably reduces the intensities of all CL peaks observed. Figure 1 also shows that implantation-produced defects do not give rise to any new luminescent bands in the visible part of the spectrum, which is consistent with luminescence studies of ion implanted $\mathrm{GaN}$ reported previously (see, for example, Refs. 2, 13, 21, and 45-49). Hence it can be concluded that intrinsic lattice defects, produced by ion bombardment (i.e., point defect complexes and some planar defects, as identified previously ${ }^{42}$ ), mainly act as efficient nonradiative recombi- nation centers, resulting in a strong decrease in CL intensity. This conclusion is also supported by the annealing studies discussed below.

The extent of CL quenching by ion bombardment is roughly proportional to the amount of lattice damage produced. This can be clearly seen from a comparison of CL intensities shown in Fig. 1 with the number of ion-beamgenerated lattice vacancies given in Table II. Previous CL depth-profiling studies ${ }^{49}$ have shown that, for implant and CL conditions similar to those used in this study, CL generation within the implanted layer is dramatically quenched. In this case, the detected CL signal is generated by the electron beam impinging on virgin $\mathrm{GaN}$, beyond the implanted layer. Hence, a further quenching of CL emission with an increase in implantation-produced lattice disorder (see CL spectra in Fig. 1 for the cases of implantation with $\mathrm{H}, \mathrm{C}$, and $\mathrm{O}$ ions) can be attributed to an increase in the extent of defect-related light absorption within the implanted layer. ${ }^{49}$

The fact that CL generation within the implanted layer is dramatically quenched may also explain (i) a preferential quenching of near-gap emission compared to the other emission peaks observed in Fig. 1 and (ii) a redshift (of $\sim 40$ $\mathrm{meV}$ ) of the near-gap emission peak in the spectra obtained from ion implanted $\mathrm{GaN}$ as compared to spectra obtained from as-grown $\mathrm{GaN}$ (see Fig. 1). Indeed, both self-absorption $^{33,50}$ and defect-induced absorption of CL in the implanted layer ${ }^{49}$ can dramatically affect the intensity and peak position of the detected near-gap emission coming from underlying virgin GaN.

\section{B. Thermal annealing of implantation damage}

As shown above, implantation-produced lattice defects act as very efficient nonradiative recombination centers. Therefore, in order to study the effects of implanted species on CL emission, such lattice defects must be removed. In this study, we used a RTA treatment at temperatures up to $1050{ }^{\circ} \mathrm{C}$ to anneal implantation damage. However, it should be noted that annealing even at such high temperatures is not sufficient to completely remove lattice defects produced even by the relatively low dose light-ion bombardment used in this study (see Table II for implant conditions). Previous CL depth-profiling studies ${ }^{49}$ of light-ion implanted $\mathrm{GaN}$ have shown that annealing at temperatures up to $1050^{\circ} \mathrm{C}$ usually does not completely recover CL emission coming from the thin near-surface layer directly modified by ion bombardment.

The apparent recovery of detected luminescence by such annealing, which has been observed experimentally, ${ }^{2,13,21,45-49}$ has been attributed to (i) thermally induced recovery of lattice defects that enhance the absorption of light within the implanted layer and (ii) recovery of CL emission in the ion end-of-range region, where the concentration of implantation-produced defects is sufficiently low so that most of these defects can be effectively removed by such annealing. ${ }^{49}$ Indeed, previous studies ${ }^{49}$ have shown that CL emission is restored in the ion end-of-range region, where the level of implantation disorder is relatively low, but the concentration of implanted species is relatively high. ${ }^{51,52}$ 


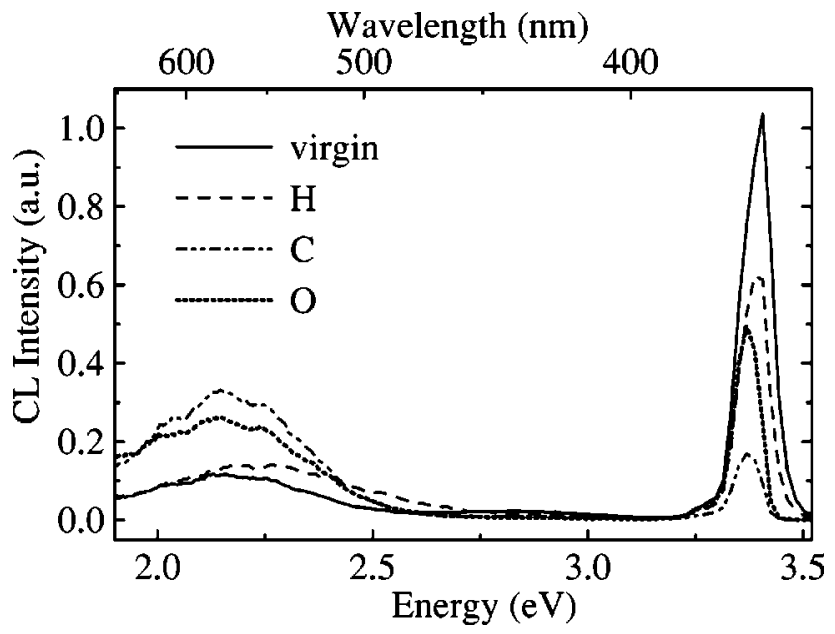

FIG. 2. CL spectra obtained at $300 \mathrm{~K}$ from GaN implanted with $\mathrm{H}, \mathrm{C}$, and $\mathrm{O}$ ions, as indicated in the legend, and subsequently annealed at $1050{ }^{\circ} \mathrm{C}$ for $15 \mathrm{~s}$ (wafer $\mathrm{C}$, electron beam energy $=20 \mathrm{keV}$, electron beam current $=8.6$ $\mathrm{nA}, \mathrm{CL}$ bandpass $=2.5 \mathrm{~nm}$ ). The details of implant conditions are given in Table II.

Hence, a RTA treatment with annealing temperatures up to $1050{ }^{\circ} \mathrm{C}$ can be applied to study the optical effects of implanted species, although CL emission within most of the implanted layer can be dramatically quenched even after such annealing.

\section{Role of implanted species}

First of all, it should be noted that, from all species implanted $(\mathrm{H}, \mathrm{B}, \mathrm{C}, \mathrm{N}, \mathrm{O}$, and $\mathrm{Si}$ ), only $\mathrm{H}, \mathrm{C}$, and $\mathrm{O}$ have been found to be involved in YL. Indeed, introduction of $\mathrm{B}, \mathrm{N}$, and $\mathrm{Si}$ (to ion doses up to $\sim 10^{14} \mathrm{~cm}^{-2}$ ) into all $\mathrm{GaN}$ samples studied did not result in an enhancement of the intensity of YL. Therefore, we will concentrate below on the role of $\mathrm{H}$, $\mathrm{C}$, and $\mathrm{O}$ in the formation of the YL band.

Shown in Fig. 2 are CL spectra obtained at $300 \mathrm{~K}$ from $\mathrm{GaN}$ implanted with $\mathrm{H}, \mathrm{C}$, or $\mathrm{O}$ ions and subsequently annealed at $1050{ }^{\circ} \mathrm{C}$ for $15 \mathrm{~s}$. It is seen that, in contrast to implantation with other species used, $\mathrm{H}, \mathrm{C}$, and $\mathrm{O}$ implantation results in an increase in the intensity of YL. ${ }^{53}$ It should be noted that thermal annealing at $1050^{\circ} \mathrm{C}$ had a negligible

TABLE III. The intensities of near-gap (NG) and YL peaks obtained from samples cut from GaN wafers A, B, and C (see Table I) implanted with $\mathrm{H}$, $\mathrm{C}$, and $\mathrm{O}$ ions. The details of implant conditions are given in Table II. CL intensities were normalized to the intensities of corresponding NG and YL peaks in the unimplanted parts of the samples (electron beam energy $=20$ $\mathrm{keV}, \mathrm{CL}$ bandpass $=2.5 \mathrm{~nm}$ ).

\begin{tabular}{|c|c|c|c|c|c|c|}
\hline \multirow[b]{2}{*}{ Species } & \multicolumn{2}{|c|}{ Wafer A } & \multicolumn{2}{|c|}{ Wafer B } & \multicolumn{2}{|c|}{ Wafer C } \\
\hline & NG & YL & NG & YL & NG & YL \\
\hline virgin & 1.0 & 1.0 & 1.0 & 1.0 & 1.0 & 1.0 \\
\hline $\mathrm{H}$ & 0.679 & 1.011 & 0.779 & 2.618 & 0.613 & 1.391 \\
\hline C & 0.206 & 1.698 & 0.217 & 1.971 & 0.169 & 2.793 \\
\hline $\mathrm{O}$ & 0.207 & 0.477 & 0.372 & 3.088 & 0.477 & 2.203 \\
\hline $\mathrm{C}+\mathrm{H}$ & 0.190 & 2.295 & 0.342 & 3.118 & 0.169 & 3.447 \\
\hline $\mathrm{O}+\mathrm{H}$ & 0.201 & 0.510 & 0.407 & 3.382 & 0.477 & 4.284 \\
\hline $\mathrm{C}+\mathrm{O}$ & 0.144 & 1.348 & 0.224 & 3.324 & 0.303 & 10.523 \\
\hline $\mathrm{C}+\mathrm{O}+\mathrm{H}$ & 0.141 & 1.424 & 0.342 & 3.765 & 0.303 & 13.860 \\
\hline
\end{tabular}

effect on the CL intensities from as-grown GaN samples used in this study. Table III gives the intensities of near-gap and YL peaks (normalized to the corresponding values of the intensities in the unimplanted parts of these samples) taken from representative samples $\mathrm{A}, \mathrm{B}$, and $\mathrm{C}$ implanted with $\mathrm{H}$, $\mathrm{C}$, and $\mathrm{O}$ ions. $\mathrm{CL}$ measurements performed at $77 \mathrm{~K}$ reveal qualitatively similar results to those shown in Fig. 2 and Table III for CL data obtained at $300 \mathrm{~K}$. Below, we discuss the role of each of these species separately.

It should be noted that previous studies on redistribution of dopants implanted into $\mathrm{GaN}$ have shown that $\mathrm{C}, \mathrm{O}$, and $\mathrm{Si}$ exhibit negligible diffusion during RTA used in this study (i.e., $15 \mathrm{~s}$ at $1050{ }^{\circ} \mathrm{C}$ ). ${ }^{1}$ Although $\mathrm{H}$ generally shows some diffusion in $n$-type $\mathrm{GaN}$ at temperatures above $\sim 800^{\circ} \mathrm{C}$, results of previous studies ${ }^{1}$ as well as our secondary ion mass spectrometry (SIMS) studies indicate that a significant fraction of $\mathrm{H}$ still remains within the $\mathrm{GaN}$ film after annealing at $1050^{\circ} \mathrm{C}$ for $15 \mathrm{~s}$, presumably, due to the affinity of $\mathrm{H}$ to decorate as-grown and implantation-produced lattice defects. However, longer anneals (such as $\gtrsim 2 \mathrm{~min}$ at $1050^{\circ} \mathrm{C}$ ) of $\mathrm{H}$-implanted samples have revealed a reduction in YL intensity, suggesting an effective out-diffusion of $\mathrm{H}$ atoms from the GaN film, which is consistent with previous reports on the redistribution of $\mathrm{H}$ in $\mathrm{GaN} .{ }^{1}$

\section{Oxygen}

Figure 2 and Table III show that implantation of $\mathrm{O}$ into some $\mathrm{GaN}$ samples (such as those cut from wafers $\mathrm{B}$ and $\mathrm{C}$ ) enhances the intensity of the YL band. However, in other samples (as represented by wafer A in Table III), the introduction of $\mathrm{O}$ does not result in an increase in the intensity of YL. This result is consistent with some previous implantation studies, ${ }^{13,21}$ which suggests that $\mathrm{O}$ may participate in the formation of the YL band. Although the exact role of $\mathrm{O}$ in $\mathrm{YL}$ is not clear at present, it appears that $\mathrm{O}$ acts as a shallow donor involved in YL. Such a conclusion is supported by the fact that the introduction of $\mathrm{O}$ by ion implantation enhances YL only in the samples with relatively low initial concentrations of free carriers $\left(\leqslant 1 \times 10^{16} \mathrm{~cm}^{-3}\right)$, as can be seen from Tables I and III. Moreover, our additional results show that implantation of $\mathrm{O}$ (with an energy of $150 \mathrm{keV}$ and to doses up to $\sim 1 \times 10^{14} \mathrm{~cm}^{-2}$ ) into several $\mathrm{Si}$ doped $\mathrm{GaN}$ samples with initial free electron concentrations from $\sim 5 \times 10^{16}$ to $5 \times 10^{18} \mathrm{~cm}^{-3}$ does not result in an increase in the intensity of YL (as measured either before or after postimplantation annealing). Hence, taking into account the currently most plausible model for the energy transitions involved in $\mathrm{YL},{ }^{3}$ we attribute the increase in YL intensity caused by $\mathrm{O}$ implantation into samples with low initial free electron concentration (see Tables I and III) to a formation of donor-acceptor pairs (DAPs) involving $\mathrm{O}$ atoms, which are known to act as relatively shallow donors in $\mathrm{GaN},{ }^{1,54}$ and deep acceptors unintentionally introduced into GaN during crystal growth. ${ }^{55}$

\section{Carbon}

Figure 2 and Table III, as well as a number of previous experimental studies, ${ }^{2,3,7,13,14,20,21,28,38}$ clearly indicate that $\mathrm{C}$ is involved in the complex responsible for the YL band in $\mathrm{GaN}$. Indeed, it has been shown that introduction of $\mathrm{C}$ (either 
during crystal growth or by ion implantation) always significantly enhances the intensity of YL in MOCVD grown GaN, as clearly illustrated in Fig. 2 and Table III. Indeed, in this study, implantation of $\mathrm{C}$ into six different $\mathrm{GaN}$ wafers (with initial free electron concentrations up to $5 \times 10^{18} \mathrm{~cm}^{-3}$, grown by MOCVD in three different laboratories) always resulted in a strong enhancement of the intensity of the YL band, as measured after postimplantation annealing. In addition, our studies show that an enhancement of YL is observed only for implantation to moderate doses of $\mathrm{C}$ ions ( $\approx 10^{13} \mathrm{~cm}^{-2}$ of $120 \mathrm{keV} \mathrm{C}$ ions, corresponding to the introduction of $\gtrsim 10^{18} \mathrm{~cm}^{-3}$ of $\mathrm{C}$ atoms), while a lower dose $\mathrm{C}$ ion implantation (say, $\sim 10^{12} \mathrm{~cm}^{-2}$ of $120 \mathrm{keV} \mathrm{C}$ ions) does not result in an enhancement of YL. This latter result is consistent with the fact that the concentration of background $\mathrm{C}$ impurities, unintentionally introduced during MOCVD growth, is usually of the same order of magnitude; i.e., $\gtrsim 10^{17}-10^{18} \mathrm{~cm}^{-3}$ (Ref. 1).

Another interesting effect, which can be observed from Figs. 1 and 2 as well as from Table III, is that, in addition to giving rise to YL, C-related complexes appear to act as efficient nonradiative recombination centers. Indeed, as can be seen from Table II, bombardment of GaN with $120 \mathrm{keV} \mathrm{C}$ ions produces $\sim 1.6$ times fewer atomic displacements than irradiation with $150 \mathrm{keV} \mathrm{O}$ ions. This difference in the damage levels produced by different ions is directly reflected by the extent of the quenching of CL emission in as-implanted samples (without postimplantation annealing), as shown in Fig. 1. However, Fig. 2 and Table III illustrate that, after postimplantation annealing, the intensity of near-gap emission in C-implanted samples is significantly lower than that in O-implanted samples, despite a large difference in the concentration of ion-beam-generated atomic displacements for $\mathrm{C}$ and $\mathrm{O}$ ion bombardment. This effect may be attributed to participation of $\mathrm{C}$ in complexes which act as efficient nonradiative recombination centers (or centers with low radiative recombination probability) and result in a decrease in the intensity of near-gap emission.

Other possible scenarios for the effect of preferential quenching of all CL peaks by implantation with $\mathrm{C}$ ions are (i) the trapping of defects at $\mathrm{C}$-related complexes during thermal annealing, which may result in the suppression of the efficiency of defect removal during annealing and (ii) involvement of $\mathrm{C}$ in defect-impurity complexes which act as strong light absorbers and, hence, affect detected CL intensities. However, the former scenario does not seem to be plausible since the concentration of $\mathrm{C}$ atoms introduced is rather low $\left(\leqslant 6 \times 10^{18} \mathrm{~cm}^{-3}\right)$ to significantly affect the thermally induced removal of implantation-produced defects. The latter scenario also seems unlikely since an RTA treatment at $1050{ }^{\circ} \mathrm{C}$ results in a complete restoration of the original sample color in the cases of all three implants $(\mathrm{H}, \mathrm{C}$, and $\mathrm{O}$ ), which suggests an efficient recovery of light absorbing defects. Indeed, as-implanted samples grown on sapphire substrates have a yellowish-brown appearance, while annealing at $1050^{\circ} \mathrm{C}$ completely recovers the apparent transparency of implanted samples to that of as-grown $\mathrm{GaN}$.

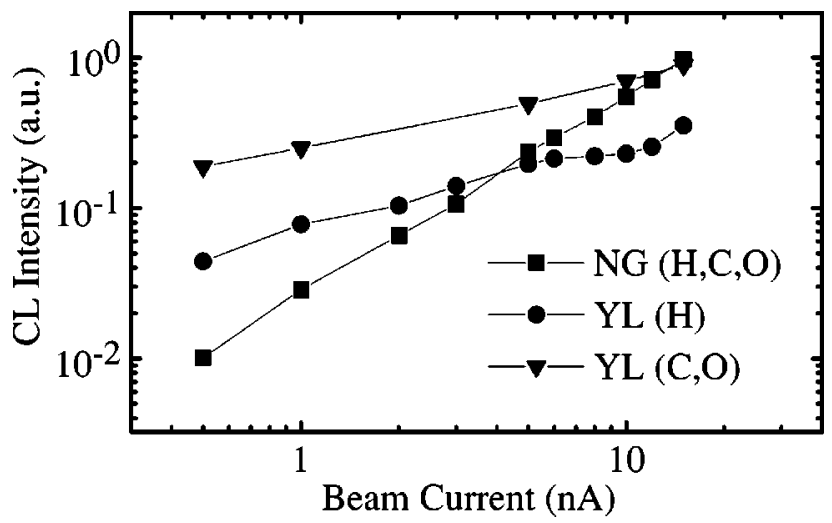

FIG. 3. The intensities of near-gap (3.39 eV) and YL (2.15 eV) peaks measured at $300 \mathrm{~K}$ from GaN samples implanted with $\mathrm{H}, \mathrm{C}$, and $\mathrm{O}$ ions (as indicated in the legend), and subsequently annealed at $1050{ }^{\circ} \mathrm{C}$ for $15 \mathrm{~s}$, as a function of electron beam current obtained with a finely focused electron beam (wafer B, electron beam energy $=20 \mathrm{keV}, \mathrm{CL}$ bandpass $=2.5 \mathrm{~nm}$, scan size $\approx 80 \times 100 \mu \mathrm{m}^{2}$ ). The details of implant conditions are given in Table II.

\section{Hydrogen}

Figure 2 shows a typical spectrum of a $\mathrm{H}$-implanted and subsequently annealed $\mathrm{GaN}$ sample, which clearly shows that implantation of $\mathrm{H}$ produces a broad luminescent band (centered on $\sim 2.25 \mathrm{eV})$ which is slightly $(\sim 0.1 \mathrm{eV}$ for wafer C) blueshifted relative to the C-related YL peak. This result suggests that $\mathrm{H}$ also participates in the formation of the $\mathrm{YL}$ band in $\mathrm{GaN}$, as will be discussed more fully below.

\section{Excitation density studies}

Our excitation density measurements taken from $\mathrm{C}$ and $\mathrm{O}$ ion implanted and subsequently annealed GaN have not revealed any detectable shift in the position of the YL band for the range of excitation densities used (for electron beam currents from 0.5 up to $15 \mathrm{nA}$ with an electron beam energy of $20 \mathrm{keV}$ ). However, the results of similar excitation studies of H-implanted and subsequently annealed samples have shown that, with a 30-fold increase in excitation density, the H-related YL band undergoes a detectable blueshift (for example, a blueshift of $\sim 7 \mathrm{meV}$ in the case of wafer B) ${ }^{56}$ Such a blueshift suggests that DAP recombination may be involved in the formation of the H-related YL band. ${ }^{57,58}$ However, a blueshift with increasing excitation density may also be due to other processes such as (i) band filling, (ii) a reduction in band-bending if YL is due to radiative transitions involving surface states, and/or (iii) saturation of a lower energy peak if YL is comprised of several broad overlapping peaks. These possible processes have previously been reported to explain photoluminescence data. ${ }^{1,57,59}$ However, it is rather unlikely that band filling is responsible for such a blueshift since the position of other peaks, including neargap emission, does not change with increasing excitation density. The involvement of surface states in the radiation transition responsible for YL in ion implanted samples also seems to be unlikely. Indeed, our CL depth profiling studies have shown that, even after postimplantation annealing used in this study, YL is suppressed in the very near-surface layer, as was discussed in Sec. III B. Hence the most plausible explanations for the blueshift observed in $\mathrm{H}$-implanted 
samples are DAP transitions and the saturation of a smaller energy peak if the YL band is comprised of several broad overlapping peaks. Additional studies are required to distinguish between these two scenarios.

The effect of excitation density on the YL band is also illustrated in Fig. 3, which shows the intensities of near-gap and YL in $\mathrm{H}-, \mathrm{C}-$, and $\mathrm{O}$-implanted and subsequently annealed samples as a function of electron beam current. It is seen from Fig. 3 that, in contrast to C- and O-implanted samples, the intensity of the YL band in the H-implanted sample exhibits a more complex behavior with changing excitation density. Such dependencies of the intensity and position of the YL band on excitation density (see the above discussion and Fig. 3) suggest that the YL band in H-implanted GaN consists of at least two contributions: (i) $\mathrm{H}$-related YL and (ii) C-related YL, as discussed more fully below. Hence several radiative recombination channels (at least two: $\mathrm{H}$ - and $\mathrm{C}$-related) can contribute to the YL band, which is consistent with a number of previous studies. ${ }^{20,22,25,34}$

\section{E. Chemical origin of YL}

In this section, we discuss the chemical origin of YL based on our data as well as on the results previously reported in the literature. First of all, a number of reports, including this one, show that the chemical origin of YL is not simple, which may explain the apparent contradiction and complexity of the results on the properties of YL reported in the literature. ${ }^{1}$ In agreement with previous reports, ${ }^{20,22,25,34}$ our data shows that YL consists of several (at least two: Hand C-related) luminescence bands overlapping in the same spectral region. Hence several radiative recombination channels contribute to the YL band.

We emphasize that our data shows that lattice defects alone do not give rise to YL. Indeed, bombardment of GaN with species such as B, N, or Si produces lattice defects but does not emphasize YL. Postimplantation annealing of these samples also does not result in an increase in the intensity of $\mathrm{YL}$ as compared to the corresponding intensity of $\mathrm{YL}$ in as-grown GaN samples. An apparent contradiction between our results and the results of previous luminescence studies of ion implanted GaN reported by Pankove and Hutchby, ${ }^{2}$ where most of the implants have been shown to result in a strong increase in the intensity of $\mathrm{YL}$, may be reconciled as follows. Assuming that a C-defect complex is involved in the formation of YL, one can speculate that ion-beam-produced lattice defects forming complexes with $\mathrm{C}$ atoms, unintentionally introduced into $\mathrm{GaN}$ during crystal growth, were responsible for the ion-beam-induced increase in the intensity of YL reported in Ref. 2. Such a scenario is strongly supported by the fact that most of the GaN crystals grown in the 1970s had a very large background concentration of impurities such as $\mathrm{C}$ and $\mathrm{O} .{ }^{60}$

As discussed above, the intrinsic origin of YL (i.e., lattice defects alone) is not supported by our experimental data. Some impurities should be involved in the center responsible for YL. From the possible candidates, strong experimental evidence exists in favor of $\mathrm{C}$. Indeed, experimental studies show that introduction of $\mathrm{C}$ either during crystal growth $^{3,7,20,28}$ or by ion implantation (Refs. 2, 13, 21, and results herein) into MOCVD grown $\mathrm{GaN}$ always strongly enhances the intensity of the YL band. Introduction of other species does not consistently have such an effect on the intensity of YL. An important role of C in the formation of YL in $\mathrm{GaN}$ has also been supported by photoionization spectroscopy experiments recently reported by Klein et al. ${ }^{38}$

Despite such strong and unambiguous experimental evidence, the important role of $\mathrm{C}$ in the formation of $\mathrm{YL}$ is generally not recognized at present. Indeed, in a recent report, Neugebauer and Van de Walle ${ }^{10}$ have theoretically investigated a number of possible configurations of $\mathrm{C}$ in $\mathrm{GaN}$ (including several $\mathrm{C}$-defect complexes). They have found that, within the theoretical treatment used, $\mathrm{C}$ does not give rise to any deep acceptor level in GaN with low formation energy. Hence they have concluded that $\mathrm{C}$ cannot be directly involved in $\mathrm{YL}^{10}{ }^{10}$ This theoretical result has also been confirmed by other calculations reported by Boguslawski et al. ${ }^{16}$ However, it is clear that none of the theoretical calculations can counter the strong experimental evidence of the important role of $\mathrm{C}$ in the formation of YL. This latter conclusion is also supported by obvious limitations of the theoretical approaches used to calculate the properties of deep centers in semiconductors, especially given the complexity of the real complex involved in YL as well as the present immaturity of GaN.

Our data also shows that implantation of $\mathrm{O}$ enhances $\mathrm{YL}$ only in samples with a relatively low initial concentration of free carriers, suggesting that shallow donor levels associated with $\mathrm{O}$ are involved in DAP transitions presumably responsible for YL. However, at present, additional studies are needed to better understand the role of $\mathrm{O}$ in the formation of the YL band in GaN.

Finally, our data (see Fig. 2 and Sec. III D) indicates that $\mathrm{H}$ is also involved in a complex giving rise to a luminescence band in the yellow spectral region. This result is consistent with previous reports by Zhang and Kuech, ${ }^{20,22}$ who have shown that an introduction of $\mathrm{H}$ during $\mathrm{GaN}$ crystal growth results in a strong YL band with properties (such as temperature dependence of photoluminescence intensity) different from those of the C-related YL band. However, at this stage, the microscopic model for the H-related complex which gives rise to the above H-related YL band is not clear, and this issue requires additional systematic studies.

\section{CONCLUSIONS}

The chemical origin of the YL band in $\mathrm{GaN}$ has been studied by ion implantation and CL spectroscopy. Results have indicated that $\mathrm{H}, \mathrm{C}$, and $\mathrm{O}$, presumably in combination with point defects, are involved in the formation of the YL in $\mathrm{GaN}$, while lattice defects alone (as well as the other species implanted such as $\mathrm{B}, \mathrm{N}$, and $\mathrm{Si}$ ) do not give rise to YL. In addition to giving rise to $\mathrm{YL}, \mathrm{C}$-related complexes appear to act as efficient nonradiative recombination centers. Our data strongly suggests that several (at least two: $\mathrm{H}-$ and C-related) radiative recombination channels contribute to the formation of the YL band. The H-related YL band is slightly blue- 
shifted relative to the C-related YL band in the case of relatively high excitation densities. This H-related peak exhibits a DAP-like behavior (i.e., a blueshift with increasing excitation density), while the position of the C-related peak does not show any detectable shift for the range of excitation densities used in this study. The results of this study may have significant implications for the development of an adequate microscopic model for the YL band in GaN.

\section{ACKNOWLEDGMENTS}

The authors would like to thank H. Boudinov for helping with electrical measurements as well as M. Linnarsson and B. Svensson for SIMS measurements.

${ }^{1}$ See, for example, reviews J. W. Orton and C. T. Foxon, Rep. Prog. Phys. 61, 1 (1998); S. J. Pearton, J. C. Zolper, R. J. Shul, and F. Ren, J. Appl. Phys. 86, 1 (1999); S. C. Jain, M. Willander, J. Narayan, and R. Van Overstraeten, ibid. 87, 965 (2000), and references therein.

${ }^{2}$ J. I. Pankove and J. A. Hutchby, J. Appl. Phys. 47, 5387 (1976); Appl. Phys. Lett. 24, 281 (1974).

${ }^{3}$ T. Ogino and M. Aoki, Jpn. J. Appl. Phys. 19, 2395 (1980).

${ }^{4}$ E. R. Glaser, T. A. Kennedy, K. Doverspike, L. B. Rowland, D. K. Gaskill, J. A. Freitas, Jr., M. Asif Khan, D. T. Olson, J. N. Kuznia, and D. K. Wickenden, Phys. Rev. B 51, 13326 (1995).

${ }^{5}$ D. M. Hofmann, D. Kovalev, G. Steude, B. K. Meyer, A. Hoffmann, L. Eckey, R. Heitz, T. Detchprom, H. Amano, and I. Akasaki, Phys. Rev. B 52, 16702 (1995).

${ }^{6}$ P. Perlin, T. Suski, H. Teisseyre, M. Leszczynski, I. Grzegory, J. Jun, S. Porowski, P. Boguslawski, J. Bernholc, J. C. Chervin, A. Polian, and T. D. Moustakas, Phys. Rev. Lett. 75, 296 (1995); T. Suski, P. Perlin, H. Teisseyre, M. Leszczynski, I. Grzegory, J. Jun, M. Bockowski, S. Porowski, and T. D. Moustakas, Appl. Phys. Lett. 67, 2188 (1995).

${ }^{7}$ R. Niebuhr, K. Bachem, K. Dombrowski, M. Maier, W. Pletschen, and U. Kaufmann, J. Electron. Mater. 24, 1531 (1995).

${ }^{8}$ W. Grieshaber, E. F. Schubert, I. D. Goepfert, R. F. Karlicek, Jr., M. J. Schurman, and C. Tran, J. Appl. Phys. 80, 4615 (1996).

${ }^{9}$ M. Banas, G. Liu, J. Ramer, K. Zheng, S. Hersee, and K. Malloy, Mater. Res. Soc. Symp. Proc. 395, 813 (1996).

${ }^{10}$ J. Neugebauer and C. G. Van de Walle, Appl. Phys. Lett. 69, 503 (1996).

${ }^{11}$ F. A. Ponce, D. P. Bour, W. Gotz, and P. J. Wright, Appl. Phys. Lett. 68, 57 (1996).

${ }^{12}$ P. de Mierry, O. Ambacher, H. Kratzer, and M. Stutzmann, Phys. Status Solidi A 158, 587 (1996).

${ }^{13}$ E. Silkowski, Y. K. Yeo, R. L. Hengehold, M. A. Khan, T. Lei, K. Evans, and C. Cerny Mater. Res. Soc. Symp. Proc. 395, 813 (1996).

${ }^{14}$ A. Y. Polyakov, M. Shin, J. A. Freitas, M. Skowronski, D. W. Greve, and R. G. Wilson, J. Appl. Phys. 80, 6349 (1996)

${ }^{15}$ E. Calleja, F. J. Sánchez, D. Basak, M. A. SánchezGarcá, E. Muñoz, I. Izpura, F. Calle, J. M. G. Tijero, J. L. SánchezRojas, B. Beaumont, P. Lorenzini, and P. Gibart, Phys. Rev. B 55, 4689 (1997).

${ }^{16}$ P. Boguslawski and J. Bernholc, Phys. Rev. B 56, 9496 (1997); P. Boguslawski, E. L. Briggs, and J. Bernholc, Appl. Phys. Lett. 69, 233 (1996).

${ }^{17}$ K. Saarinen, T. Laine, S. Kuisma, J. Nissilä, P. Hautojärvi, L. Dobrzynski, J. M. Baranowski, K. Pakula, R. Stepniewski, M. Wojdak, A. Wysmolek, T. Suski, M. Leszczynski, I. Grzegory, and S. Porowski, Phys. Rev. Lett. 79, 3030 (1997).

${ }^{18}$ H. M. Chen, Y. F. Chen, M. C. Lee, and M. S. Feng, Phys. Rev. B 56, 6942 (1997).

${ }^{19}$ C. V. Reddy, K. Balakrishnan, H. Okumura, and S. Yoshida, Appl. Phys. Lett. 73, 244 (1998).

${ }^{20}$ R. Zhang and T. F. Kuech, Appl. Phys. Lett. 72, 1611 (1998).

${ }^{21}$ R. Zhang, L. Zhang, N. Perkins, and T. F. Kuech, Mater. Res. Soc. Symp. Proc. 512, 321 (1998).

${ }^{22}$ R. Zhang and T. F. Kuech, J. Electron. Mater. 27, L35 (1998).

${ }^{23}$ J. Elsner, R. Jones, M. I. Heggie, P. K. Sitch, M. Haugk, Th. Frauenheim, S. Öberg, and P. R. Briddon, Phys. Rev. B 58, 12571 (1998).

${ }^{24}$ M. Toth, K. Fleischer, and M. R. Phillips, Phys. Rev. B 59, 1575 (1999).

${ }^{25}$ J. S. Colton, P. Y. Yu, K. L. Teo, E. R. Weber, P. Perlin, I. Grzegory, and K. Uchida, Appl. Phys. Lett. 75, 3273 (1999); J. S. Colton, P. Y. Yu, K. L.
Teo, P. Perlin, E. R. Weber, I. Grzegory, and K. Uchida, Physica B 273274, 75 (1999).

${ }^{26}$ I. Shalish, L. Kronik, G. Segal, Y. Rosenwaks, Y. Shapira, U. Tisch, and J. Salzman, Phys. Rev. B 59, 9748 (1999).

${ }^{27}$ U. Kaufmann, M. Kunzer, H. Obloh, M. Maier, Ch. Manz, A. Ramakrishnan, and B. Santic, Phys. Rev. B 59, 5561 (1999).

${ }^{28}$ U. Birkle, M. Fehrer, V. Kirchner, S. Einfeldt, D. Hommel, S. Strauf, P. Michler, and J. Gutowski, MRS Internet J. Nitride Semicond. Res. 4S1, G6.6 (1999).

${ }^{29}$ M. A. Reshchikov, F. Shahedipour, R. Y. Korotkov, M. P. Ulmer, and B. W. Wessels, Physica B 273-274, 105 (1999).

${ }^{30}$ X. Li, P. W. Bohn, and J. J. Coleman, Appl. Phys. Lett. 75, 4049 (1999).

${ }^{31}$ G. Salviati, M. Albrecht, C. Zanotti-Fregonara, N. Armani, M. Mayer, Y. Shreter, M. Guzzi, Yu. V. Melnik, K. Vassilevski, V. A. Dmitriev, and H. P. Strunk, Phys. Status Solidi A 171, 325 (1999).

${ }^{32} \mathrm{G}$. Li, S. J. Chua, S. J. Xu, W. Wang, P. Li, B. Beaumont, and P. Gibart, Appl. Phys. Lett. 74, 2821 (1999).

${ }^{33}$ K. Fleischer, M. Toth, M. R. Phillips, J. Zou, G. Li, and S. J. Chua, Appl. Phys. Lett. 74, 1114 (1999)

${ }^{34}$ F. K. Koschnick, K. Michael, J.-M. Spaeth, B. Beaumont, and P. Gibart, Appl. Phys. Lett. 76, 1828 (2000).

${ }^{35}$ M. W. Bayerl, N. M. Reinacher, H. Angerer, O. Ambacher, M. S. Brandt, and M. Stutzmann, Appl. Phys. Lett. 88, 3249 (2000).

${ }^{36}$ Y.-H. Kwon, S. K. Shee, G. H. Gainer, G. H. Park, S. J. Hwang, and J. J. Song, Appl. Phys. Lett. 76, 840 (2000).

${ }^{37}$ A. Hierro, D. Kwon, S. A. Ringel, M. Hansen, J. S. Speck, U. K. Mishra, and S. P. DenBaars, Appl. Phys. Lett. 76, 3064 (2000).

${ }^{38}$ P. B. Klein, S. C. Binari, K. Ikossi, A. E. Wickenden, D. D. Koleske, and R. L. Henry, Appl. Phys. Lett. 79, 3527 (2001).

${ }^{39}$ An alternative model for YL proposed by Glaser et al. (Ref. 4), that YL is due to a radiative transition from a deep donor to a shallow acceptor, has not been supported by subsequent experiments reported in Refs. 6, 26, and 34.

${ }^{40}$ See, for example, A. M. Stoneham, Theory of Defects in Solids: Electronic Structure of Defects in Insulators and Semiconductors (Clarendon, Oxford, 1975).

${ }^{41}$ J. P. Biersack and L. G. Haggmark, Nucl. Instrum. Methods 174, 257 (1980).

${ }^{42}$ S. O. Kucheyev, J. S. Williams, C. Jagadish, J. Zou, and G. Li, Phys. Rev. B 62, 7510 (2000); S. O. Kucheyev, J. S. Williams, C. Jagadish, J. Zou, G. Li, and A. I. Titov, ibid. 64, 035202 (2001).

${ }^{43}$ The fact that simple point defects in GaN appear to be mobile at room temperature has also been discussed in V. V. Emtsev, V. Yu. Davydov, V. V. Kozlovskii, D. S. Poloskin, A. N. Smirnov, N. M. Shmidt, and A. S. Usikov, Physica B 273-274, 101 (1999); K. H. Chow, G. D. Watkins, A. Usui, and M. Mizuta, Phys. Rev. Lett. 85, 2761 (2000).

${ }^{44}$ See, for example, A. Billeb, W. Grieshaber, D. Stocker, E. F. Schubert, and R. F. Karlicek, Jr., Appl. Phys. Lett. 70, 2790 (1997).

${ }^{45}$ B. J. Pong, C. J. Pan, Y. C. Teng, G. C. Chi, W.-H. Li, K. C. Lee, and C.-H. Lee, J. Appl. Phys. 83, 5992 (1998).

${ }^{46}$ A. Suvkhanov, J. Hunn, W. Wu, D. Thomson, K. Price, N. Parikh, E. Irene, R. F. Davis, and L. Krasnobaev, Mater. Res. Soc. Symp. Proc. 512, 475 (1998).

${ }^{47}$ C. Ronning, E. P. Carlson, D. B. Thomson, and R. F. Davis, Appl. Phys. Lett. 73, 1622 (1998).

${ }^{48}$ S. O. Kucheyev, J. S. Williams, C. Jagadish, J. Zou, M. Toth, M. R. Phillips, H. H. Tan, G. Li, and S. J. Pearton, Mater. Res. Soc. Symp. Proc. 622, T7.9.1 (2000).

${ }^{49}$ S. O. Kucheyev, M. Toth, M. R. Phillips, J. S. Williams, C. Jagadish, and G. Li, Appl. Phys. Lett. 78, 34 (2001).

${ }^{50}$ K. Knobloch, P. Perlin, J. Krueger, E. R. Weber, and C. Kisielowski, MRS Internet J. Nitride Semicond. Res. 3, 4 (1998).

${ }^{51}$ This interesting result can be explained as follows. In the first approximation, the depth distributions of implanted species and atomic displacements, generated by the ion beam, can be described by the first moments $\left(R_{p}\right.$ and $R_{p_{d}}$ for the distributions of ion ranges and atomic displacements, respectively) and by the second central moments $\left(\Delta R_{p}\right.$ and $\Delta R_{p_{d}}$ for ion ranges and atomic displacements, respectively) (Ref. 52). Because $R_{p}$ $>R_{p_{d}}$ (always) and $\Delta R_{p}>\Delta R_{p_{d}}$ (in the case of light ions as used in this study) (Ref. 52), the depth distribution of implanted species is shifted deeper into the crystal bulk with respect to the distribution of atomic displacements. Hence, there is a layer in the ion end-of-range region where the concentration of implanted species is relatively high, while the 
amount of implantation damage, produced both by ballistic collisional processes and due to defect migration, is sufficiently low to be successfully recovered by the annealing treatment used in this study.

${ }^{52}$ See, for example, M. A. Kumakhov and F. F. Komarov, Energy Loss and Ion Ranges in Solids (Gordon and Breach, New York, 1981).

${ }^{53}$ Figure 2 also shows a small redshift of the near-gap emission peak in the spectra obtained from C- and O-implanted samples as compared to spectra obtained from as-grown and $\mathrm{H}$-implanted $\mathrm{GaN}$. This redshift can be attributed to defect-induced absorption of CL emission within the implanted layer, as discussed in Sec. III A. The absence of such a redshift in the case of $\mathrm{GaN}$ implanted with $\mathrm{H}$ ions and subsequently annealed suggests that postimplantation annealing effectively recovers (though only partially) $\mathrm{CL}$ emission within the layer damaged by $\mathrm{H}$ ion bombardment.

${ }^{54}$ B.-C. Chung and M. Gershenzon, J. Appl. Phys. 72, 651 (1992).

${ }^{55}$ It should be noted that the involvement of $\mathrm{Si}$ in the YL band previously reported in Refs. 27 and 36 might be somewhat similar to that of $\mathrm{O}$ discussed here; i.e., $\mathrm{Si}$ acts as a shallow donor. However, the effect of self-compensation (see, for example, Ref. 27) which may result in the formation of deep acceptor traps (involving, presumably, intrinsic defects as well as $\mathrm{H}$ and/or $\mathrm{C}$, as discussed below) participating in YL seems to be a more plausible explanation for the effects of Si doping reported in Refs.
27 and 36. Indeed, ion implantation results reported here and elsewhere (Refs. 13 and 21) show that introduction of Si itself does not enhance the intensity of YL.

${ }^{56}$ It should be noted that our detailed kinetics profiling studies show that kinetics effects (i.e., the effects of electron-beam-induced modification of GaN during CL measurements) are very weak and can be neglected in the interpretation of CL data from the ion implanted and subsequently annealed GaN samples used in this study.

${ }^{57}$ See, for example, J. I. Pankove, Optical Processes in Semiconductors (Dover, New York, 1971).

${ }^{58}$ This conclusion follows from (i) the inverse dependence of peak energy on donor-acceptor pair separation and (ii) a reduction in the transition probability with increasing pair separation. As a result, at higher excitation densities, widely separated pairs are saturated, and the contribution from radiative recombination at closely separated pairs increases, leading to a blueshift in the position of the peak maximum.

${ }^{59}$ M. A. Reshchikov, P. Visconti, and H. Morkoç, Appl. Phys. Lett. 78, 177 (2001).

${ }^{60}$ See, for example, J. I. Pankove, in GaN and Related Materials, edited by S. J. Pearton (Gordon and Breach, New York, 1997) 